\title{
EFICIÊNCIA AGRONÔMICA DE FERTILIZANTES FOSFATADOS FLUIDOS E SÓLIDOS $(1)$
}

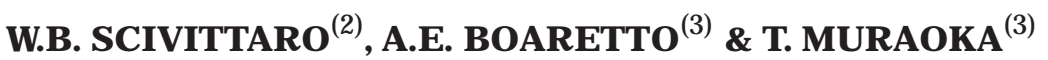

\begin{abstract}
RESUMO
Um experimento para avaliar a eficiência agronômica de ferti lizantes fosfatados fluidos e sólidos foi desenvolvido em casa de vegetação no Centro de Energia Nuclear na Agricultura - CE NA/USP, em Piracicaba (SP), de junho a outubro de 1992. Plantas de milho foram cultivadas durante $\mathbf{3 0}$ dias, por três cultivos sucessivos, em vasos contendo $1 \mathrm{~kg}$ de dois latossolos vermel ho-amarelos com diferentes capacidades de retenção de fósforo. Os fosfatos na forma fluida - áci do fosfórico e suspensão coloidal 10-30-00 e sólida - fosfato monoamônico e superfosfato triplo foram aplicados no primeiro cultivo nas doses $0,70,140$ e $210 \mathrm{mg} \mathrm{kg}^{-1}$ de $_{2} \mathrm{O}_{5}\left(0,30,6,61,2\right.$ e $91,8 \mathrm{mg} \mathrm{kg}^{-1}$ de $P$ ). Avaliaram-se os tratamentos pelo rendi mento de matéria seca, pela absor ção de fósforo e pelos índices: de eficiência agronômica (IEA) e equivalente em superfosfato triplo (EqST). Os resultados indicaram não haver diferenças entre as fontes fosfatadas fluidas e sólidas quanto ao seu efeito sobre a produção de matéria seca e absorção de fósforo pelas plantas de milho. Entretanto, a aplicação de doses crescentes dos fosfatos aos solos promoveu aumentos significativos no rendimento de matéria seca e absorção de fósforo. E m ambos os solos, a eficiência agronômica dos fertilizantes fosfatados fluidos e sólidos foi semelhante.
\end{abstract}

Termos de indexação: fosfatos, ácido fosfórico, suspensão coloidal 10-30-00, eficiência agronômica.

\section{SUMMARY: AGRONOMIC EFFECTIVENESS OF FLUID AND SOLID PHOSPHATE FERTILIZERS}

The effectiveness of fluid (phosphoric acid and 10-30-00 colloidal suspension) and solid (monoammonium phosphateand triplesuperphosphate) fertilizers was evaluated in a greenhouse experiment at the Center for Nuclear Energy in Agriculture (CENA), University of São Paulo, Piraci caba, State of São Paulo, Brazil, from J une to October, 1992. Corn plants were grown in pots (8 plants per pot; 3 replicates) containing $1 \mathrm{~kg}$ of two red-yel low latosols with different phosphorus retention capacities, for three successive cydes (30 days each). The fertilizers were applied prior to first sowing at rates of 0 (control), 70, 140 and $210 \mathrm{mg} \mathrm{kg}^{-1}$ of $\mathrm{P}_{2} \mathrm{O}_{5}(0,30.6$, 61.2 and $91.8 \mathrm{mg} \mathrm{kg}^{-1}$ of P). Plants were weighed for dry matter yield and analysed for phosphorus uptake Indexes of agronomic efficiency and equivalent of triple superphosphate

\footnotetext{
(1) Parte da Dissertação de Mestrado do primeiro autor, CENA/USP, Piracicaba (SP), 1993. Trabalho financiado pela Fundação de Amparo à Pesquisa do Estado de São Paulo. Recebido para publicação em agosto de 1996 e aprovado em maio de 1997.

(2) Pesquisadora Científica, Instituto Agronômico. Caixa Postal 28, CEP 13001-970 Campinas (SP).

(3) Pesquisador Científico, Centro de Energia Nuclear na Agricultura/USP. Caixa Postal 96, CEP 13400-970 Piracicaba (SP).
} 


\begin{abstract}
were calculated. Results showed no difference between the effects of fluid and solid phosphate fertilizers on dry matter yield and phosphorus uptake However, therates of phosphorus applied weresignificantly and positivel y related with dry matter yiel d and phosphorus uptake In both soils, the agronomi c effectiveness of fluid and solid phosphate fertilizers was equival ent.
\end{abstract}

Index terms: phosphates, phosphoric acid, 10-30-00 col loi dal suspension, agronomic effectiveness.

\section{INTRODUÇÃO}

A característica que melhor avalia uma fonte de fósforo, do ponto de vista agronômico, éa sua eficiência em fornecer o nutriente para as plantas, ou seja, sua capacidade de provocar o maior acréscimo de rendimento por unidade de P aplicado (Goedert \& Sousa, 1984). Pel o fato de o efeito dos fertilizantes ser dependente de fatores pedológi cos eclimáticos, do tipo de manejo e do ecossistema solo-planta, a eficiência agronômica dos fosfatos é, em geral, calculada pela comparação com uma fonte de referência (Morel \& Fardeau, 1990), como os superfosfatos simples e triplo (Raij, 1986).

No Brasil, as pesquisas com avaliação agronômica de fontes de fósforo aumentaram consideravel mente a partir do início da década dos setentas, em face da elevação dos preços dos fertilizantes fosfatados solúveis e da dependência do País de seu suprimento do exterior (Braga et al., 1980, e Defilippe, 1990). Desde essa época, a procura por fontes alternativas de fertilizantes fosfatados tem sido uma preocupação constante (N ogueira, 1990).

O emprego de fertilizantes fluidos como fonte alternativa para o suprimento de fósforo para as culturas ainda é pequeno. No entanto, são promissoras as perspectivas de crescimento do seu consumo, tendo em vista as vantagens que oferecem em relação aos fertilizantes aplicados na forma sólida: facilidade de armazenamento e aplicação, maior uniformidade de aplicação, minimização de perdas, versatilidade de formulações, menor consumo de mão-de-obra e redução do custo da adubação.

No tocante à eficiência agronômica dos fertilizantes fluidos, muito pouco é conhecido. Entretanto, de acordo com Silva et al. (1988), fertilizantes fluidos e sólidos possuem eficiência semel hante quando utilizados nas mesmas doses de nutrientes e condições de aplicação. Até o momento, os poucos estudos realizados, no Brasil, com o intuito de avaliar a eficiência de fertilizantes fosfatados fluidos concentraram-se, princi palmente, na cultura da cana-de-açúcar (Silva et al., 1988; K orndörfer, 1990, e Penatti, 1991), havendo carência de informações relativas a outras culturas.

Com base no exposto, foi desenvolvido um experimento para avaliar a eficiência agronômica de alguns fertilizantes fosfatados fluidos e sólidos, utilizando como planta indicadora o milho.

\section{MATERIAL E MÉTODOS}

O experimento foi realizado em casa de vegetação no Centro de Energia Nudear na Agricultura - CENA/USP, de junho a outubro de 1992, utilizando-se amostras superficiais $(0-20 \mathrm{~cm})$ de dois solos, classificados por Oliveira \& Prado (1984) como latossolo vermel hoamarelo álico $A$ proeminente textura muito argilosa U nidade Itororó (LV Itororó) e latossolo vermelhoamarelo álico $A$ proeminente textura média Unidade Três Barras (LV Três Barras). As amostras de solo foram secas ao ar, passadas em peneira com abertura de mal ha de $2 \mathrm{~mm}$, homogeneizadas e caracterizadas química e fisicamente (Quadro 1).

A correção da acidez dos solos foi feita visando atingir o valor 6,0 para o $\mathrm{pH}\left(\mathrm{CaCl}_{2}\right)$, pela aplicação de quantidades de calcário dol omítico cal cinado (PRNT $=130 \%$ ) correspondentes às doses: 10,8 e 3,9 t ha-1 para o LV I tororó e LV Três Barras, respectivamente.

Os tratamentos empregados, para cada solo, compreenderam as combinações de quatro fertilizantes fosfatados (Quadro 2): o ácido fosfórico $(\mathrm{AF})$ e a suspensão col oidal 10-30-00(4) $(\mathrm{SC})$, na forma fluida, e fosfato monoamônico (MAP) e superfosfato

Quadro 1. Características químicas e físicas de amostras dos latossolos vermelho-amarelos unidades Itororó e Três Barras

\begin{tabular}{|c|c|c|}
\hline Características & Itororó & Três Barras \\
\hline $\mathrm{pH}, \mathrm{CaCl}_{2} 0,01 \mathrm{~mol} \mathrm{~L}^{-1}$ & 4,1 & 4,2 \\
\hline M.O., g dm-3 (1) & 63 & 29 \\
\hline 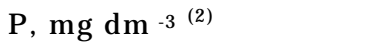 & 3 & 2 \\
\hline $\mathrm{K}^{+}, \mathrm{mmol}_{\mathrm{c}} \mathrm{dm}^{-3}{ }^{(2)}$ & 1,1 & 1,0 \\
\hline $\mathrm{Ca}^{2+}, \mathrm{mmol}_{\mathrm{c}} \mathrm{dm}^{-3}{ }^{(2)}$ & 4 & 3 \\
\hline $\mathrm{Mg}^{2+}, \mathrm{mmol}_{\mathrm{c}} \mathrm{dm}^{-3}(2)$ & 1 & 1 \\
\hline $\mathrm{H}+\mathrm{Al}, \mathrm{mmol}_{\mathrm{c}} \mathrm{dm}^{-3}(3)$ & 150 & 61 \\
\hline $\mathrm{Al}^{3+}, \mathrm{mmol}_{\mathrm{c}} \mathrm{dm}^{-3}(4)$ & 14 & 7 \\
\hline $\mathrm{CTC}, \mathrm{mmol}_{\mathrm{c}} \mathrm{dm}^{-3}$ & 156,1 & 66,0 \\
\hline Saturação por bases, \% & 4 & 8 \\
\hline CF $P, \mathrm{mg} \mathrm{g}^{-1}(5)$ & 1230 & 525 \\
\hline Areia grossa, $\mathrm{g} \mathrm{kg}^{-1}{ }^{(6)}$ & 160 & 270 \\
\hline Areia fina, $\mathrm{g} \mathrm{kg}^{-1}(6)$ & 200 & 590 \\
\hline Silte, $\mathrm{g} \mathrm{kg}^{-1}(6)$ & 80 & 0 \\
\hline Argila, $\mathrm{g} \mathrm{kg}^{-1}(6)$ & 560 & 140 \\
\hline
\end{tabular}

(1) Método colorimétrico (Raij et al., 1987). ${ }^{(2)}$ Resina trocadora de íons (Raij et al., 1987). ${ }^{(3)}$ Método SMP (Raij et al., 1987). ${ }^{(4)} \mathrm{KCl}$ 0,1 mol L-1 (Raij et al., 1987). ${ }^{(5)}$ Capacidade de fixação de fósforo (Thomazi, 1988). ${ }^{(6)}$ Método do densímetro (Bouyoucos, 1927).

\footnotetext{
(4) Fertilizante fluido obtido pela reação deácido fosfórico com amônia anidra, sendo parte dos nutrientes mantidos suspensos no meio líquido pela ação de um agente geleificante.
} 
Quadro 2. Características químicas e forma física das fontes de fósforo

\begin{tabular}{llccc}
\hline $\begin{array}{c}\text { Fonte } \\
\text { de } \mathbf{P}^{(1)}\end{array}$ & $\begin{array}{c}\text { Forma } \\
\text { física }\end{array}$ & $\begin{array}{c}\mathbf{P}_{\mathbf{2}} \mathbf{O}_{\mathbf{5}} \\
\text { total }\end{array}$ & $\begin{array}{c}\mathbf{P}_{\mathbf{2}} \mathbf{O}_{\mathbf{5}} \\
\text { água }\end{array}$ & $\begin{array}{c}\mathbf{P}_{\mathbf{2}} \mathbf{O}_{\mathbf{5}} \mathbf{C N A}^{(2)} \\
\text { + água }\end{array}$ \\
\hline & & & $\%$ & \\
AF & Líquida & 47,71 & 45,68 & 46,41 \\
SC & Líquida & 27,84 & 26,33 & 27,22 \\
MAP & Sólida (pó) & 54,45 & 52,27 & 53,35 \\
ST & Sólida (pó) & 48,57 & 37,54 & 47,88 \\
\hline
\end{tabular}

(1) AF: ácido fosfórico; SC: suspensão coloidal 10-30-00; MAP: fosfato monoamônico, e ST: superfosfato triplo. ${ }^{(2)}$ CNA: Citrato neutro de amônio.

triplo (ST), na forma de pó, e quatro doses de fósforo: $0,70,140$ e $210 \mathrm{mg} \mathrm{kg}^{-1}$ de $\mathrm{P}_{2} \mathrm{O}_{5}(0,30,6,61,2$ e $91,8 \mathrm{mg} \mathrm{kg}^{-1}$ de $\mathrm{P}$ ), calculadas com base no teor de $\mathrm{P}_{2} \mathrm{O}_{5}$ total de cada fonte. Os tratamentos constituíram um fatorial $4 \times 4 \times 2$, dispostos em delineamento de blocos ao acaso, com três repetições, sendo as unidades experimentais representadas por vasos contendo $1 \mathrm{~kg}$ de terra seca ao ar.

Cada vaso recebeu adubação básica com nitrogênio (nitrato deamônio - $70 \mathrm{mg} \mathrm{kg}^{-1}$ de $\mathrm{N}$ ), potássio(d oreto de potássio - $120 \mathrm{mg} \mathrm{kg}^{-1}$ de K) e micronutrientes (solução nutritiva completa (Sarruge, 1975), na dose de $1 \mathrm{~mL} \mathrm{kg-1}$ ). Essas fontes de nutrientes foram misturadas às amostras de solo e, em seguida, fez-se a adubação fosfatada, segundo os tratamentos, de forma localizada, em sul co com $3 \mathrm{~cm}$ de profundidade, aberto diametral mente nos vasos.

Realizaram-se três cultivos sucessivos de 30 dias com o milho híbrido AG-403B, mantendo-se oito plantas em cada vaso, efetuando-se o segundo e o tercei ro após a remoção das raízes e revol vimento do solo contido nos vasos. Ambos receberam adubação nitrogenada, potássica e com micronutrientes, semel hante à do primeiro cultivo.

Durante os cultivos, a umidade do sol ofoi mantida próxima a $80 \%$ de sua capacidade máxima de retenção de água. Aplicaram-se, em cobertura, soluçỗes contendo $160 \mathrm{mg} \mathrm{kg}^{-1}$ de $\mathrm{N}$, na forma de sulfato de amônio, parceladas em quatro aplicações semanais, e $120 \mathrm{mg} \mathrm{kg}^{-1} \mathrm{de} \mathrm{K}$, na forma de cloreto de potássio, em duas aplicações quinzenais.

O material vegetal (parte aérea e raízes), após a lavagem em água detorneira e destilada, edeionizada, foi seco em estufa com circulação forçada do ar, a $65^{\circ} \mathrm{C}$ por 72 horas, pesado, moído e analisado quanto ao conteúdo de fósforo, segundo método descrito por Bataglia et al. (1983).

Os tratamentos foram avaliados pelo rendimento de matéria seca e pel o fósforo absorvido pel as plantas, os quais permitiram o cál culo dos índices de eficiência agronômica (IEA) eequival enteem superfosfato triplo (E qST), descritos por Goedert et al. (1986). Na determinação do IEA, o parâmetro produção foi expresso pel o somatório das produções dematéria seca e de fósforo absorvido nos três cultivos. Esse índice foi calculado para as doses: 70,140 e $210 \mathrm{mg} \mathrm{kg}^{-1}$ de $\mathrm{P}_{2} \mathrm{O}_{5}$ e EqST, para as doses de fosfato que proporcionaram $90 \%$ da produção máxima obtida com o superfosfato triplo.

$\mathrm{Na}$ análise estatística, o teste $\mathrm{F}$ foi utilizado na comparação de médias do fator solo. Para a comparação das médias de fontes de fósforo, empregou-se o teste deTukey ao nível de $5 \%$ e, para a aval iação dos efeitos dos níveis de fósforo, realizaramse análises de regressão pol inomial.

\section{RESULTADOS E DISCUSSÃO}

Comparando dados de produção de matéria seca ao longo dos cultivos (Quadro 3), observa-se que, para os tratamentos com adição de fosfato, esses foram menores no segundo cultivo, que coincidiu com um período de baixas temperaturas, limitando o desenvol vimento da cultura. Por outro lado, na ausência de fósforo, a quantidade de matéria seca aumentou do primeiro para o terceiro cultivo, indicando que os sucessivos cultivos estimularam a liberação de fósforo nativo do solo para as plantas e, conseqüentemente, seu crescimento.

Quanto à absorção de fósforo pelo mi lho (Quadro 4), essa se manteve praticamente constante, ao longo dos cultivos, nos tratamentos testemunha. Nos demais, verificou-se decréscimo na absorção de $\mathrm{P}$ a partir do primeiro cultivo, refletindo redução no potencial de suprimento de fósforo dos solos devida à exportação do nutriente no cultivo I eà intensificação das reações de fixação dos fosfatos causada pel o revolvimento do solo após os cultivos. Para ambas as características, houve resposta das plantas à aplicação de fosfatos desde o primeiro cultivo, o que indica imediata disponibilidade do $\mathrm{P}$ das fontes utilizadas.

A produção de matéria seca ea absorção de fósforo foram significativamente maiores noLVTrês Barras, quando comparadas às do LV I tororó (Quadros 3 e 4). I sso podeser atribuído à menor capacidade de fixação de fósforo do primeiro solo (Quadro 1), visto que as diferenças entre solos no fornecimento de $\mathrm{P}$ para as plantas estão intimamente relacionadas à sua capacidade de retenção de fosfato, sendo que em sol os com baixo potencial de fixação de $\mathrm{P}$, a disponibilidade do el emento para as plantas é el evada, refletindo em maior absorção de fósforo e produção (Volk \& McL ean, 1961; Novoa \& N unez, 1974; Goedert \& Sousa, 1984).

As fontes de fósforo não diferiram estatisticamente entresi quanto à produção de matéria seca eabsorção de fósforo, mesmo ao longo dos cultivos (Quadros 3 e 4), demonstrando semel hança entre os fosfatos nas formas líquida e sólida no fornecimento de P para as plantas de milho. Esses dados confirmam aqueles obtidos por Silva et al. (1988); Korndörfer (1990) e Penatti (1991), para a cultura da cana-de-açúcar. 
Quadro 3. Produção de matéria seca das plantas de milho nos latossolos vermelho-amarelos, em função de fontes e doses de fosfato, unidades Itororó e Três Barras

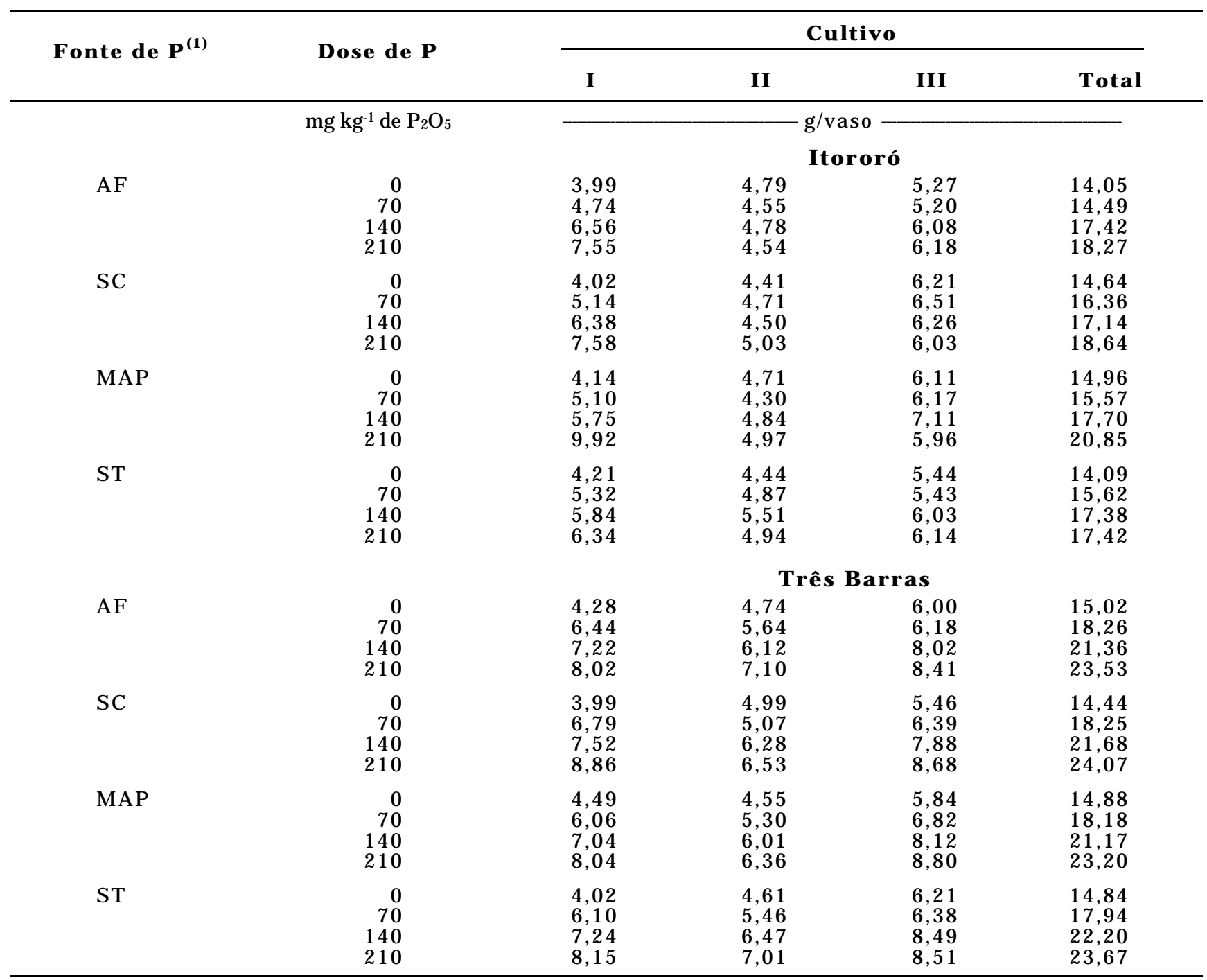

(1) AF: ácido fosfórico; SC: suspensão coloidal 10-30-00; MAP: fosfato monoamônico, e ST: superfosfato triplo.

Verificou-se, para ambos os solos, efeito altamente significativo das doses de fósforo sobre o somatório das quantidades de matéria seca produzidas nos três cultivos. O aumento da dose de P aplicada promoveu respostas positivas e lineares, para todas as fontes de fosfato (Figuras 1 e 2), indicando que o rendimento de matéria seca poderia ter sido maior, caso tivessem sido utilizadas doses mais el evadas de fosfato. No entanto, para o LV Itororó, esses resultados não refletiram o comportamento observado nos cultivos II e III, cujas respostas à variação no nível de P não foram significativas, exceção feita ao áci do fosfórico no cultivolll (dados não apresentados). Esses resultados indicam que, no LV I tororó, as doses de P utilizadas não influenciaram o efeito residual dos fosfatos. Comportamento semel hante ao descrito verificou-se para os dados de fósforo absorvido pelo milho.

Os IEAs relativos ao somatório dos dados de rendimento de matéria seca e fósforo absorvido pelas plantas de milho encontram-se, respectivamente, nas figuras 3 e 4, cuja análise demonstra que o comportamento agronômico dos fosfatos avaliados foi semel hante. Esse resultado era previsível, visto que as fontes utilizadas apresentam el evada sol ubilidade em água, característica que determina, em grande parte, a eficiência agronômica dos fosfatos (Webb et al.,1961; Goedert \& Sousa, 1986 eChien et al., 1990). Outro fator a ser considerado é a forma física de aplicação das fontes de fósforo, pois os fertilizantes líquidos entram em contato com maior volume de solo, em comparação aos sólidos, o que favorece as reações de fixação do fósforo, reduzindo sua disponibilidade para as plantas. Por essa razão, atribui-se a equivalência verificada, entre as fontes fluidas e sólidas, ao fato de MAP e ST terem sido aplicados na forma de pó, possibilitando íntimo contato com os constituintes do solo. É provável, porém, que, com a granulação, essas fontes sólidas apresentem desempenho superior ao das fontes fluidas. 
Quadro 4. Fósforo total absorvido pelas plantas de milho nos latossolos vermelho-amarelos, em função de fontes e doses de fosfato, unidades I tororó e Três Barras

\begin{tabular}{|c|c|c|c|c|c|}
\hline \multirow{2}{*}{ F onte de $P^{(1)}$} & \multirow{2}{*}{ Dose de P } & \multicolumn{4}{|c|}{ Cultivo } \\
\hline & & $\mathbf{I}$ & II & III & Total \\
\hline & \multirow[t]{2}{*}{$\mathrm{mg} \mathrm{kg}^{-1}$ de $\mathrm{P}_{2} \mathrm{O}_{5}$} & \multicolumn{4}{|c|}{ g/vaso } \\
\hline & & \multicolumn{4}{|c|}{ Itororó } \\
\hline$A F$ & $\begin{array}{r}0 \\
70 \\
140 \\
210\end{array}$ & $\begin{array}{r}3,95 \\
5,41 \\
8,49 \\
10,36\end{array}$ & $\begin{array}{l}4,04 \\
4,30 \\
4,26 \\
4,28\end{array}$ & $\begin{array}{l}3,76 \\
4,00 \\
5,20 \\
5,16\end{array}$ & $\begin{array}{l}11,75 \\
13,71 \\
17,95 \\
19,80\end{array}$ \\
\hline $\mathrm{SC}$ & $\begin{array}{r}0 \\
70 \\
140 \\
210\end{array}$ & $\begin{array}{r}4,11 \\
5,54 \\
7,84 \\
11,67\end{array}$ & $\begin{array}{l}3,88 \\
4,50 \\
4,13 \\
4,67\end{array}$ & $\begin{array}{l}4,61 \\
4,89 \\
4,69 \\
5,19\end{array}$ & $\begin{array}{l}12,60 \\
14,93 \\
16,66 \\
21,53\end{array}$ \\
\hline MAP & $\begin{array}{r}0 \\
70 \\
140 \\
210\end{array}$ & $\begin{array}{l}3,97 \\
5,50 \\
7,18 \\
9,70\end{array}$ & $\begin{array}{l}3,81 \\
3,90 \\
4,40 \\
4,82\end{array}$ & $\begin{array}{l}4,31 \\
4,76 \\
5,32 \\
5,05\end{array}$ & $\begin{array}{l}12,09 \\
14,16 \\
16,90 \\
19,57\end{array}$ \\
\hline \multirow[t]{2}{*}{ ST } & $\begin{array}{r}0 \\
70 \\
140 \\
210\end{array}$ & $\begin{array}{l}4,13 \\
5,81 \\
7,79 \\
8,83\end{array}$ & $\begin{array}{l}3,88 \\
4,36 \\
5,09 \\
4,49\end{array}$ & $\begin{array}{l}3,96 \\
4,27 \\
4,81 \\
4,60\end{array}$ & $\begin{array}{l}11,97 \\
14,44 \\
17,69 \\
17,92\end{array}$ \\
\hline & & \multicolumn{4}{|c|}{ Três Barras } \\
\hline$A F$ & $\begin{array}{r}0 \\
70 \\
140 \\
210\end{array}$ & $\begin{array}{r}4,39 \\
8,50 \\
11,96 \\
15,58\end{array}$ & $\begin{array}{l}4,23 \\
5,10 \\
6,02 \\
7,18\end{array}$ & $\begin{array}{l}4,59 \\
5,27 \\
6,51 \\
7,09\end{array}$ & $\begin{array}{l}13,21 \\
18,87 \\
24,49 \\
29,85\end{array}$ \\
\hline $\mathrm{SC}$ & $\begin{array}{r}0 \\
70 \\
140 \\
210\end{array}$ & $\begin{array}{r}4,15 \\
9,14 \\
13,91 \\
19,44\end{array}$ & $\begin{array}{l}4,44 \\
4,62 \\
6,03 \\
6,44\end{array}$ & $\begin{array}{l}4,20 \\
5,23 \\
6,30 \\
7,21\end{array}$ & $\begin{array}{l}12,79 \\
18,99 \\
26,24 \\
33,09\end{array}$ \\
\hline MAP & $\begin{array}{r}0 \\
70 \\
140 \\
210\end{array}$ & $\begin{array}{r}4,35 \\
7,19 \\
12,20 \\
17,19\end{array}$ & $\begin{array}{l}3,96 \\
4,98 \\
5,95 \\
6,18\end{array}$ & $\begin{array}{l}4,24 \\
4,86 \\
6,82 \\
7,59\end{array}$ & $\begin{array}{l}12,55 \\
17,03 \\
24,97 \\
30,96\end{array}$ \\
\hline ST & $\begin{array}{r}0 \\
70 \\
140 \\
210\end{array}$ & $\begin{array}{r}4,06 \\
7,83 \\
11,76 \\
14,42\end{array}$ & $\begin{array}{l}3,97 \\
5,21 \\
6,35 \\
6,99\end{array}$ & $\begin{array}{l}4,08 \\
5,03 \\
6,95 \\
7,71\end{array}$ & $\begin{array}{l}12,11 \\
18,07 \\
25,06 \\
29,12\end{array}$ \\
\hline
\end{tabular}

(1) AF: ácido fosfórico; SC: suspensão coloidal 10-30-00; MAP: fosfato monoamônico, e ST: superfosfato triplo.

Ainda pelas figuras 3 e 4 , pode-se notar que as diferenças entre os valores dos IEAs, determinados para os níveis de fosfato 70, 140 e $210 \mathrm{mg} \mathrm{kg}^{-1} \mathrm{de}_{2} \mathrm{O}_{5}$, foram pequenas. Isso é explicado pel o fato de os níveis avaliados pertencerem à porção ascendente da curva de resposta ao fósforo, o que confere maior precisão ao IEA, uma vez que esse foi estabelecido para respostas lineares à adição de P. Para todas as fontes de fósforo, os IEAs calculados a partir dos dados de rendimento de matéria seca e fósforo absorvido pelas plantas de milho foram próximos, evidenciando que ambas as características discriminaram, de maneira satisfatória, a eficiência agronômica dos fosfatos.

A eficiência agronômica das fontes de fósforo estudadas foi, também, avaliada mediante o índice equival ente em superfosfato triplo (EqST) (Figuras 1 e 2). De acordo com Goedert et al. (1986), esse índice é mais preciso que o de eficiência agronômica, pois leva em consideração a forma real da curva de resposta às fontes de P. Os índices E qST encontrados diminuíram nas seguintes ordens: SC (128\%) > MAP (108\%) > ST (100\%) >AF (85\%), para o LV Itororó, e ST $(100 \%)=$ SC $(100 \%)>$ MAP $(92 \%)>$ AF $(83 \%)$, para o LV Três Barras. Os valores dos EqSTs, observados no presente estudo, para o ácido fosfórico, foram ligeiramente superiores aos relatados por Penatti (1991). Em ambos os solos, o EqST do AF foi inferior ao dos demais fosfatos. É provável que esse resultado esteja relacionado ao efeito da acidez provocada no solo por essa fonte de P, que afeta o desenvolvimento das plantas (Massanori, 1991, e Rabello, 1991).

Os resultados indicam que, para culturas de ciclo curto, como o milho, as fontes líquidas avaliadas são bastante promissoras por conter o fósforo em formas prontamente disponíveis às plantas. 

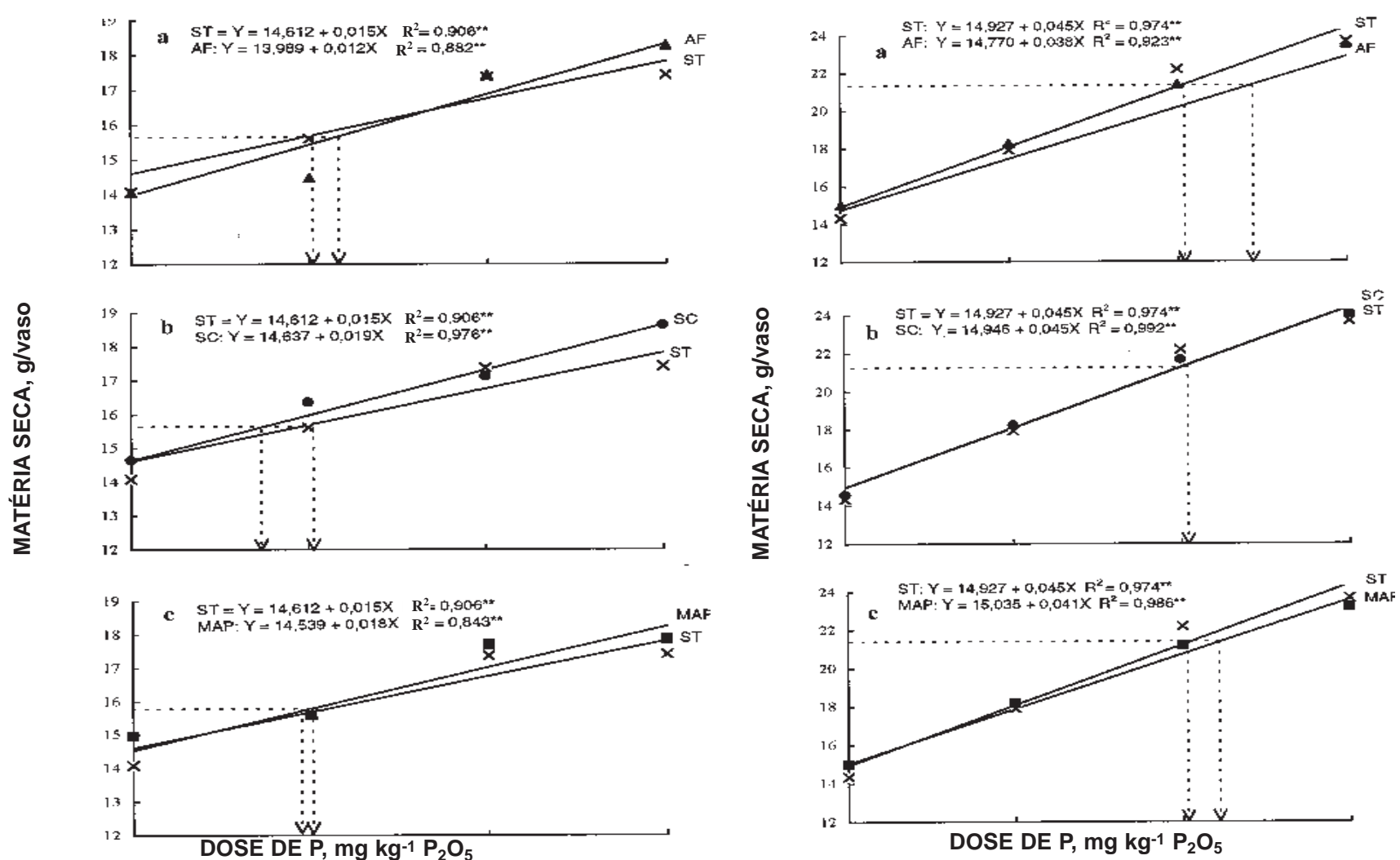

Figura 1. Produção de matéria seca das plantas de milho, em função de doses de fosfato no latossolo vermelho-amarelo, unidade Itororó. A inclusão das linhas pontilhadas ilustra o cálculo do equivalente em superfosfato triplo (EqST) para o ácido fosfórico (a), suspensão coloidal 10-30-00 (b) e fosfato monoamônico (c) (AF : ácido fosfórico; SC: suspensão coloidal 10-30-00; MAP: fosfato monoamônico; e ST: superfosfato triplo).

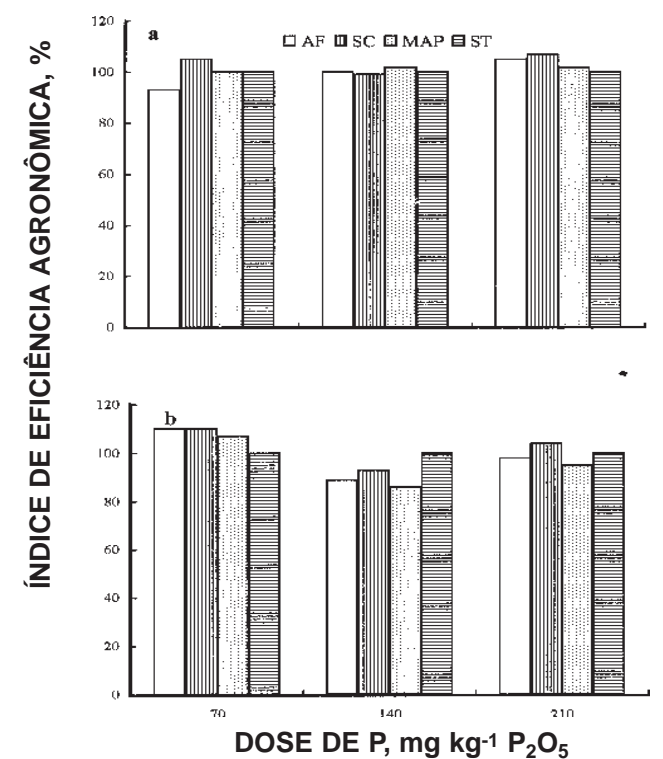

Figura 3. Índices de eficiência agronômica relativos aos dados de produção de matéria seca obtidos nos latossolos vermelho-amarel os, unidades I tororó (a) eTrês Barras (b) (AF : ácido fosfórico; SC: suspensão coloidal 10-30-00; MAP: fosfato monoamônico, e ST: superfosfato triplo).

Figura 2. Produção de matéria seca das plantas de milho, em função de doses de fosfato no latosssolo vermelho-amarelo, unidade Três Barras. A inclusão das linhas pontilhadas ilustra o cálculo do equivalente em superfosfato tri plo (E qST) para o ácido fosfórico (a), suspensão coloidal 10-30-00 (b) e fosfato monoamônico (c) (AF : ácido fosfórico; SC: suspensão coloidal 10-30-00; ; MAP: fosfato monoamônico; e ST: superfosfato triplo).

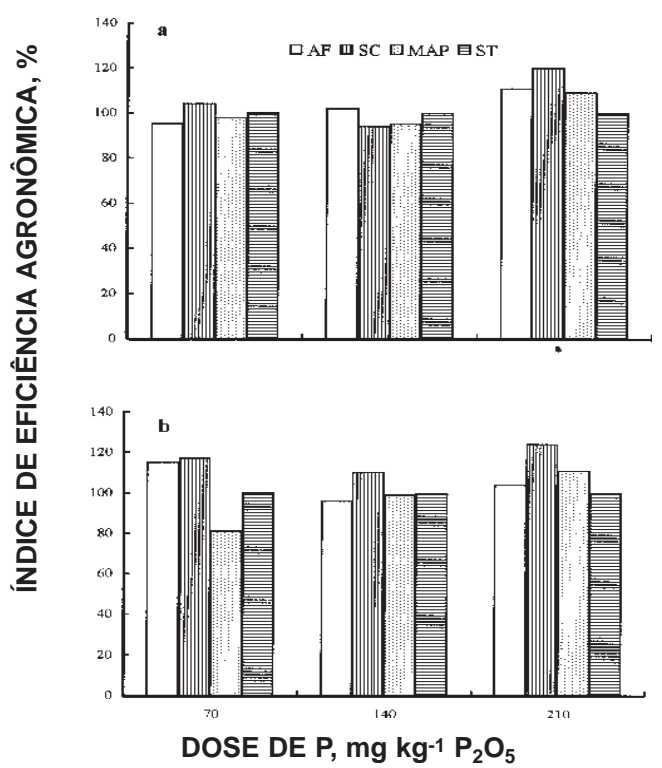

Figura 4. Índices de eficiência agronômica relativos aos dados de absorção de fósforo obtidos nos latossolos vermelho-amarelos, unidades Itororó (a) e Três Barras (b) (AF: ácido fosfórico; SC: suspensão coloidal 10-30-00; MAP: fosfato monoamônico, e ST: superfosfato triplo). 


\section{CONCLUSÕES}

1. As fontes fosfatadas fluidas e sólidas não diferiram entre si quanto ao seu efeito sobre a produção de matéria seca e absorção de fósforo pelas plantas de milho.

2. A aplicação de doses crescentes dos fosfatos aos solos promoveu aumentos lineares na produção de matéria seca e na quantidade de fósforo absorvido pelas plantas de milho. $\mathrm{O}$ efeito da adição de fontes de $P$ foi mais pronunciado no LV Três Barras devidoà sua menor capacidade de fixação de fósforo.

3. Em ambos os solos, a eficiência agronômica dos fertilizantes fosfatados fluidos (ácido fosfórico e suspensão coloidal 10-30-00) e sólidos (fosfato monoamônico e superfosfato triplo) foi comparável, demonstrando a viabilidade de uso dessas fontes fluidas em culturas de ciclo curto, como o milho.

\section{AGRADECIMENTOS}

À Agência Internacional de Energia Atômica Projeto BRA $7500 \mathrm{FR}$, pelo apoio à realização deste trabalho.

\section{LITERATURA CITADA}

BATAGLIA, O.C.; FURLANI, A.M.C.;TEIXEIRA,J JP.F.; FURLANI, P.R. \& GALLO, J.R. Métodos de análise química de plantas. Campinas, InstitutoAgronômico, 1983. 48p. (Boletim técnico, 78)

BRAGA, J.M.; MASCARENHAS, H.A.A.; FEITOSA, C.T.; HIROCE, R. \& RAIJ, B. van. Efeitos de fosfatos sobre o crescimento e produção de soja. R. bras. Ci. Solo, Campinas, 4:36-39, 1980.

BOUYOUCOS, G.J. The hydrometer method improved for the mechanical analysis of soil. Soil Sci., Baltimore, 23:343-353, 1927.

CHIEN, S.H.; SALE, P.W.G. \& FRIESEN, D.K. A discussion of the methods for comparing the relative effectiveness of phosphate fertilizers varying in the solubility. Fert. Res., Dordrecht, 24:149-157, 1990.

DEFILIPPE, G. Panorama da rocha fosfática e ácido fosfórico. In: ENCONTRO NACIONAL DE ROCHA FOSFÁTICA, 5., São Paulo, 1990. Anais. São Paulo, IBRAFOS, s.d. p.5-9.

GOEDERT, W.J . \& SOUSA, D.M.G. Uso eficiente de fertilizantes fosfatados. In: SIMPÓSIO SOBRE FERTILIZANTES NA AGRICULTURA BRASILEIRA, Brasília, 1984. p.255-290.

GOEDERT,W.J . \& SOUSA, D.M.G. Avaliação preliminar de fosfatos com acidulação parcial. R. bras. Ci. Solo, Campinas, 10:7580, 1986.
GOEDERT, W.J .; SOUZA, D.M.G. \& REIN, T.A. Princípios metodológicos para avaliação agronômica de fontes de fósforo. Planaltina, EMBRAPA/CPAC, 1986. 22p. (Documentos, 22)

KORNDÖRFER, G.H. Fertilizantes fosfatados sólidos e fluidos na cana-de-açúcar. Piracicaba, ESALQ/USP, 1990. 91p. (Tese de Doutoramento.)

MASSANORI, M. Efeito do ácido fosfórico sobre a acidez de um solo latossolo vermel ho-escuro. U berlândia, U niversidade Federal deU berlândia, 1991. 15p. (Monografia de Graduação)

MOREL,C.\& FARDEAU, J.C.Agronomical evaluation of phosphate fertilizer as a nutrient source of phosphorus for crops: isotopic procedure. Fert. Res., Dordrecht, 24:115-122, 1990.

NOGUEIRA, A.V. Eficiência agronômica, como fertilizante, de um lodo de esgoto e de dois resíduos provenientes da industria siderúrgica. Viçosa, Universidade Federal de Viçosa, 1990. 85p. (Dissertação de Mestrado)

NOVOA, F.V. \& NUNEZ, R. Efficiency of five phosphate fertilizer sources in soils with different phosphate fixing capacities. Trop. Agric., Trinidad, 51:235-245, 1974.

OLIVEIRA, J.B. \& PRADO, H. Levantamento pedológico semidetalhado do Estado de São Paulo; quadrícula de São Carlos. II. Memorial descritivo. Campinas, Instituto Agronômico, 1984. 188p. (Boletim técnico, 98)

PENATTI, C.P. Uso de ácido fosfórico ou superfosfato triplo como fonte de fósforo para a cana-de-açucar. Piracicaba, ESALQ/ USP, 1991. 72p. (Dissertação de Mestrado)

RABELLO, M. Efeito do ácido fosfórico sobre a acidez de um solo latossolo vermel ho amarelo. Uberlândia, Universidade Federal deU berlândia, 1991. 15p. (Monografia de Graduação)

RAIJ, B. van. Condições mínimas de eficiência para fosfatos alternativos ao superfosfato. R. bras. Ci. Solo, Campinas, 10:235-239, 1986.

RAIJ, B. van; QUAGGIO, J.A.; CANTARELLA, H.; FERREIRA, M.E.; LOPES, A.S. \& BATAGLIA, O.C. Análise química do solo para fins de fertilidade. Campinas, Fundação Cargill, 1987. 170p.

SARRU GE, J .R. Soluções nutritivas. Summa Phytopat., Piracicaba, 1:231-233, 1975.

SILVA, L.C.F.; MARAFON J ÚNIOR, J.; BELTRAME, J .A.; ARAGÃO, J.A. \& ORLANDO FILHO, J. Adubação fluida na cana-de-açúcar no Estado de São Paulo. Brasil Açúcar., Rio de J aneiro, 106:27-32, 1988.

THOMAZI, M.D. Fixação de fosfato por solos do município de Piracicaba. Piracicaba, ESALQ/USP, 1988. 67p. (Dissertação de Mestrado)

VOLK, V.V. \& MCLEAN, E.O. The fate of applied phosphorus in four Ohio soil. Soil Sci. Soc. Am. Proc., Madison, 27:53-58, 1961.

WEBB, J.R.; PESEK, J.T. \& ELK, K. An evaluation of phosphorus fertilizers ranging in water solubility: III. Oat fertilization. Soil Sci. Soc. Am. Proc., Madison, 25:222-226, 1961. 